\section{Profissionalização e saberes docentes na perspectiva da formação de professores de Língua Espanhola}

Professionalization and teaching knowledge in the perspective of Spanish Language teachers training

Anelise Copetti DALLA CORTE (UNICENTRO) aneliseya@gmail.com

Cibele KRAUSE-LEMKE (UNICENTRO) cibelekl2@gmail.com

Recebido em: 30 de maio de 2018. Aceito em: 25 de nov. de 2018.
DALLA CORTE, Anelise Copetti; KRAUSE-LEMKE, Cibele.

Profissionalização e saberes docentes na perspectiva da formação de professores de Língua Espanhola. Entrepalavras, Fortaleza, v. 8, n. 3, p. 402-426, out-dez/2018.

Resumo: O processo de formação e profissionalização docente é composto por várias etapas e não pode nunca ser dado como acabado, já que envolve a construção, a aquisição e o compartilhamento de saberes ao longo de toda a trajetória profissional do professor. Em relação aos professores de línguas estrangeiras, sua formação também deve ser encarada como algo permanente, uma vez que este profissional precisa aperfeiçoar e ampliar suas habilidades e os conhecimentos necessários para ensinar, compreendendo que não há modelos infalíveis, definitivos e capazes de dar conta de todas as especificidades de sua prática pedagógica. Nesse sentido, este artigo tem como objetivo apresentare discutir, por meio da análise de relatórios de estágio supervisionado em Língua Espanhola, questões referentes à formação de professores de línguas estrangeiras e à profissionalização da carreira docente, especialmente no que tange aos saberes voltados à formação docente (TARDIF, 2005). Além disso, apresentam-se algumas considerações sobre os saberes docentes e sua pertinência para a compreensão do processo de formação de professores. Como aporte teórico para este trabalho, destacamos Tardif (2005), 
Pimenta; Lima (2012), Silva (2014) e Leffa (2001). Os principais resultados da pesquisa indicam que o estágio supervisionado ainda se constitui como elemento fundamental na construção da relação entre teoria e prática.

Palavras-chave: Formação de professores. Saberes docentes. Língua Estrangeira.

Abstract: The process of training and professionalization of teachers consists of several stages and can never be given as finished, since it involves the construction, acquisition and sharing of knowledge throughout the teacher's professional career. In the case of foreign language teachers, their training should also be considered permanent, since these professionals need to improve and broaden their skills and necessary knowledge for teaching, with the understanding that there are no infallible, definitive and capable models to deal with all the specificities of their pedagogical practice. In this sense, this article is intended to present and discuss, through the analysis of the Spanish Language teaching supervised practice reports, issues related to the training of foreign language teachers and the professionalization of the teaching career, especially with regard to the knowledge related to teacher training (TARDIF, 2005). In addition, some considerations about teaching knowledge and their relevance to the understanding of the teacher training process are presented. As a theoretical contribution to this work, we highlight Tardif (2005), Pimenta; Lima (2012), Silva (2014) and Leffa (2001). The main results of the research indicate that the supervised stage is still a fundamental element in the construction of the relationship between theory and practice.

Keywords: Teacher training. Teacher knowledge. Foreign language.

\section{Introdução}

Não resta dúvida de que para ensinar é preciso aprender a ensinar. Dessa forma, o caminho para alcançar o êxito pedagógico passa pela aquisição dos saberes necessários à prática docente, por meio da experiência pessoal e profissional do professor, ou seja, adquirindoos não apenas durante a formação, mas, também, durante a carreira profissional. É importante destacar que o processo de formação docente é, na maioria das vezes, iniciado durante a graduação, sendo indispensável o aperfeiçoamento e a atualização continuada e constante desse profissional, entendendo que a formação do docente perpassa as instâncias do conhecimento científico e metodológico.

Outra dimensão a ser considerada no processo de formação de professores é a da construção de uma postura profissional frente à docência. Pode ser considerado um dos maiores desafios dos professores formadores, hoje, preparar os futuros profissionais para o trabalho docente e para serem capazes de construir sua carreira e sua identidade, deixando de ver a escola da perspectiva de aluno e passando a vê-la como ambiente de trabalho e de articulação, aquisição e compartilhamento de saberes.

A fim de propor uma reflexão mais pontual acerca da formação de professores e de algumas das dimensões que compõem 
v. 8 (3)

$402-426$ out-dez 2018

esse processo, neste artigo discutem-se a profissionalização da prática docente, a formação de professores de línguas estrangeiras e os saberes docentes, na perspectiva do Estágio Supervisionado, por meio da análise de relatórios de estágio supervisionado em Letras-Espanhol.

Este artigo está organizado da seguinte forma: na primeira parte, apresentam-se questões relacionadas ao panorama histórico da profissionalização da carreira docente; na segunda, trata-se especificamente da formação de professores de línguas estrangeiras; na terceira, apresentam-se algumas reflexões acerca do papel do estágio supervisionado e sua relação com a formação docente; na quarta, analisamos parte do corpus da pesquisa, a qual se constitui de dados referentes ao estágio supervisionado e aos saberes curriculares e, por fim, apresentamse considerações relacionadas ao escopo do presente trabalho.

\section{Profissionalização da prática docente}

A profissionalização ${ }^{1}$ docente, assim como as demais profissões, tem uma origem que é histórica e permeada por questões sociais e políticas. Os primeiros registros relacionados à profissão docente na Europa estão vinculados à igreja: "inicialmente, a função docente desenvolveu-se de forma subsidiária e não especializada, constituindo uma ocupação secundária de religiosos ou leigos das mais diversas origens" (NÓVOA, 1999, p. 15). Posteriormente, já no século 18, o Estado se ocupava de organizar e administrar o ensino, criando e exigindo dos professores uma licença para ensinar. Segundo Nóvoa (1999), "a criação desta licença (ou autorização) é um momento decisivo do processo de profissionalização da atividade docente" (NÓVOA, 1999, p. 17), no sentido de definir o conjunto dos saberes necessários à prática do professor, constituindo, assim, a carreira docente.

A partir da ampliação dos espaços de atuação e da necessidade de uma formação mais efetiva, no século 19, há a criação de instituições formadoras que passam a formar docentes e a imprimir um caráter profissional à profissão. É nesse momento que os professores encontram espaço para reivindicar direitos, pautando-se em dois argumentos: o primeiro dava conta da relevância social de seu trabalho e o segundo,

\footnotetext{
${ }^{1}$ Neste artigo, utiliza-se a definição de profissão estabelecida por Ritzer e Walczak (1986, p. 61 apud GAUTHIER et al., 2006, p. 67), que a definem como "uma ocupação que passou por um processo de desenvolvimento que a torna capaz de convencer os outros (por exemplo, os clientes, a lei) de que ela adquiriu uma constelação de características geralmente aceitas como sendo as de uma profissão".
} 
pelas características especializadas de sua ação educativa (NÓVOA, 1999, p. 18). Já no início do século 20, a Europa experimenta uma onda de prestígio dos professores, que passam a "ser investidos de um importante poder simbólico" (NÓVOA, 1999, p. 19).

No contexto brasileiro, vários autores se ocuparam de traçar um panorama histórico da educação e formação de professores (GHIRALDELLI JR., 2009; PAGNI, 2000). Segundo esses autores, no início do século 20, os intelectuais brasileiros da época viram na expansão da educação pública uma possibilidade de romper com o modelo tradicional, inserindo-se na modernidade. Esse grupo de intelectuais defendia a educação e o saber científico como meio de consolidação do progresso, que já havia chegado a outros países (PAGNI, 2000). Por meio da educação, a elite dos anos 1920 e 1930 passa a ser responsável pela formação e transformação dos cidadãos, partícipes do progresso tão almejado no Brasil (PAGNI, 2000).

Ao longo do último século, a educação brasileira passou por vários movimentos que contribuíram na configuração do sistema educacional e dos modelos pedagógicos que temos hoje (GHIRALDELLI JR., 2009). O Movimento da Escola Nova (Movimento Escolanovista) buscava modernizar o Brasil por meio da educação. Em 1932, é lançado o Manifesto dos Pioneiros da Educação Nova, propondo um novo sistema educacional, descentrando a figura do professor, estabelecendo para este novos papéis (GHIRALDELLI JR., 2009).

Já na década de 1960, o crescimento industrial e econômico do Brasil exigiu um profissional qualificado tecnicamente para atuar nesse novo contexto (PAGNI, 2000). No entanto, isso criou uma perspectiva de esvaziamento da reflexão, voltando-se à instrumentalização e ao domínio dos saberes necessários para atuar no mundo do trabalho. Nos contextos de formação docente, a situação não era muito diferente nesse período. A esse respeito, Dornelles e Irala (2013) apregoam que

De uma formação humanista generalista dominante até o final dos anos sessenta, ingressa-se na década de setenta do século XX em um modelo tecnicista, que teve como orientação central a ideia de um professor formatado para seguir receitas preestabelecidas, a partir de uma racionalidade cega e excessivamente apegada a resultados meramente numéricos como a "nota" e o cumprimento de uma "lista de conteúdos" predeterminados pela instituição escolar ou por órgãos reguladores externos a ela, como as secretarias estaduais e municipais de educação (DORNELLES; IRALA, 2013, p. 19, aspas das autoras). 
V. 8 (3)

$402-426$ out-dez 2018

Posteriormente, nas décadas de 1970 e 1980, a Pedagogia Histórico-crítica buscava romper com o modelo tecnicista (ALVES, 2007). Nesse período, os estudos da área buscavam uma pedagogia que pudesse ir além das teorias de reprodução, contribuindo para a transformação da sociedade. A partir dessa perspectiva pedagógica, o papel do professor é o de sistematizar os métodos e processos de ensino: "ao professor cabe, então, organizar o processo educativo de tal modo a possibilitar ao aluno a apropriação da cultura historicamente elaborada pela humanidade" (ALVES, 2007, p. 270). A ideia era a de passarmos de uma perspectiva de racionalidade técnica (SCHÖN, 2008) a uma visão mais crítica da formação de professores, centrada nos saberes.

Desses movimentos, resultou a percepção da complexidade dos aspectos que envolvem o processo de formação docente e de sua atuação prática. A partir da década de 1980, os países anglo-saxônicos impulsionam os estudos sobre os saberes e profissionalização da carreira docente (TARDIF, 2005). Mais tarde, nos anos 1990, já no Brasil, os estudos sobre os saberes passam a contribuir para o desenvolvimento profissional dos professores. Nunes (2001) afirma que

é a partir da década de 1990 que se buscam novos enfoques e paradigmas para compreender a prática pedagógica e os saberes pedagógicos e epistemológicos relativos ao conteúdo escolar a ser ensinado/aprendido (NUNES, 2001, p. 28).

Nessa corrente, Perrenoud (2002, p. 78, grifos do autor) postula que "a formação não é mais transmissão de conteúdos, mas construção de experiências formativas pela aplicação e estimulação de situações de aprendizagem". Além disso, para ele, a profissionalização do professor passa pela construção de sua autonomia e responsabilidade no que se refere ao seu trabalho e sua função social (PERRENOUD, 2002).

Já para Imbernón (2014), a formação de professores deve estar pautada principalmente em demandas relacionadas à melhoria dos currículos e nas instituições educativas, na resolução de problemas pertinentes ao contexto e no processo de ensino e aprendizagem. Nesse sentido, o autor ressalta que

a formação assume um papel que transcende o ensino que pretende uma mera atualização científica, pedagógica e didática e se transforma na possibilidade de criar espaços de participação, reflexão e formação para que as pessoas aprendam e se adaptem para poder conviver com a mudança e a incerteza (IMBERNÓN, 2014, p. 15). 
Perrenoud (2002), por sua vez, destaca que os Institutos de Ensino Superior (IES) possuem um papel determinante na formação docente, visto que, "cada vez mais, a formação profissional dos professores é responsabilidade das universidades e dos institutos de ensino superior" (PERRENOUD, 2002, p. 71). A formação continuada também se coloca no centro de muitas das discussões, tanto no âmbito universitário quanto no âmbito das políticas públicas. Dornelles e Irala (2013), a esse respeito, postulam que,

Na prática, o que temos, por um lado, é uma formação inicial amplamente regulada (e atualmente engessada) por uma gama de legislações a respeito do funcionamento dos cursos superiores de licenciatura e, por outro, uma enorme abrangência e variedade de concepções a respeito de diferentes modalidades de formação continuadas, ofertadas tanto por iniciativa das universidades (atividades de extensão, cursos de especialização, mestrados profissionais e acadêmicos etc.), das secretarias de educação ou de outros órgãos (públicos, privados, ONG's etc.) ou de parcerias entre essas instâncias (DORNELLES; IRALA, 2013, p. 19-20).

Toda essa gama de modalidades e abordagens, no entanto, segundo as autoras, não está se mostrando capaz de modificar o modelo de formação que, muitas vezes, privilegia a teoria em detrimento da prática. Em relação a essa questão, Pimenta e Lima (2012) afirmam que a não relação entre teoria e prática, especialmente ao longo dos estágios supervisionados, acaba por acarretar um "empobrecimento das práticas nas escolas, o que evidencia a necessidade de explicitar porque o estágio é teoria e prática (e não teoria ou prática)" (PIMENTA; LIMA, 2012, p. 41, grifo das autoras). Atualmente, a carreira docente exige não mais um profissional tecnicista, mecânico, burocrata, adaptado à ordem social e acrítico, mas um profissional capaz de assumir seu papel enquanto educador, munido de conhecimentos científicos, culturais, contextuais, psicopedagógicos e pessoais, preparado para enfrentar os desafios reflexivamente, responsavelmente, analisando as situações que se apresentam em sua atuação de uma maneira mais ampla e efetiva.

Nesse sentido, o professor seria formado para compreender a importância de sua atuação, tornar-se pesquisador de sua prática, fazer uso do máximo de saberes e capacidades docentes, de estratégias e conhecimentos possíveis, e de maneira consciente, aprender a lidar com o instável, com o contraditório, com o novo. Segundo Leffa (1999, p. 2), o grande desafio dos professores é o de "preparar os alunos não para o mundo em que nós vivemos hoje, mas para o mundo em que eles vão viver amanhã". Além disso, segundo os PCN-LE (Parâmetros Curriculares Nacionais - Língua Estrangeira, Ensino Fundamental): 
V. 8 (3)

$402-426$ out-dez 2018

é necessário que o professor aprenda a refletir sobre sua prática de forma sistemática. É esta reflexão que vai gerar massa crítica na comunidade de professores que participa, levando ao desenvolvimento na profissão. É por esse motivo que os cursos de formação ou de formação continuada de professores de língua estrangeira têm sido cada vez mais entendidos como contextos para a reflexão por meio do envolvimento dos professores em práticas de investigação (BRASIL, 1998, p. 109).

Mesmo entendendo-se que diversas diretrizes e parâmetros curriculares norteiam as práticas nos contextos educacionais brasileiros e que, muitas vezes, esses engessam os currículos e não permitem muita autonomia por parte do professor na escolha de seus materiais e métodos, é preciso formar professores capazes de adaptar os conteúdos, os materiais e os métodos de que dispõem, por meio de uma reflexão sobre seu contexto de atuação, pois "não é a prática que é formadora, mas a reflexão sobre a prática" (NÓVOA, 2007, p. 16).

\section{A formação e a profissionalização de professores de línguas estrangeiras}

A Linguística Aplicada (LA) vem se ocupando nas últimas décadas das pesquisas relacionadas à formação de professores de línguas estrangeiras no Brasil. Vários autores têm se debruçado sobre a tarefa de traçar um panorama dessa formação, entre eles, Moita Lopes (2001), Celani (2009), Leffa (2001), Vieira-Abrahão (2010), entre outros.

No passado, o professor de língua estrangeira precisava apenas conhecer a língua que se propunha a ensinar e não havia formação, apenas treinamento para a aplicação de métodos. Nesse sentido, Kumaravadivelu (2003 apud VIEIRA-ABRAHÃO, 2010, p. 226)

caracteriza o professor formado dentro da perspectiva do treinamento como técnico passivo, aquele que aprende um conjunto de conhecimentos produzidos pela academia e o transmite aos alunos (KUMARAVADIVELU, 2003 apud VIEIRAABRAHÃO, 2010, p. 226).

Hoje, os processos de formação de professores de línguas estrangeiras enfatizam a necessidade de profissionais autônomos, agentes de mudança e empenhados em refletir sobre sua prática. Para Leffa (2001),

a formação de um professor de línguas estrangeiras envolve o domínio de diferentes áreas de conhecimento, incluindo o domínio da língua que ensina, e o domínio da ação pedagógica necessária para fazer a aprendizagem da língua acontecer em sala de aula (LEFFA, 2001, p. 334). 
Espera-se, ainda, que esse profissional seja capaz de adaptarse às variadas e, muitas vezes, adversas condições de trabalho e que esteja em constante investigação, análise e reflexão de seu fazer pedagógico. São estes alguns dos elementos indispensáveis do ser professor. Os desafios a esses profissionais residem, ainda, no fato de que deverão ensinar uma língua que não é a sua. Dessa forma, tem-se um falante usuário de uma língua adicional, que possui uma língua materna que carrega marcas históricas, identitárias e culturais, mas que acaba em contato com outra língua, igualmente marcada por esses aspectos. Esse contato permite elaborar e estabelecer relações entre ambas as línguas: materna e estrangeira. Para Nunes (2010),

a língua estrangeira vem questionar a relação que está instaurada entre o sujeito e sua língua. Essa relação é complexa e estruturante da relação que o sujeito mantém com ele mesmo, com os outros e com o saber (NUNES, 2010, p. 98).

Nunes (2010) afirma, ainda, que o estranhamento que é experimentado ao aprender uma língua estrangeira pode, inclusive, ser vivido como uma perda de identidade. Ao ensinar uma língua que não é a sua primeira, o professor de língua estrangeira precisa lidar com esse estranhamento sentido também pelo aluno, fazendo-o não apenas aceitar a diferença, mas apropriar-se dela (NUNES, 2010).

Diante das demandas que o educador de língua estrangeira encontra nos dias atuais, é imprescindível que este profissional assuma uma nova postura frente à educação e à sua própria formação. Segundo Alvarez (2010),

o professor precisa fazer suas próprias descobertas e achar as próprias respostas, por mais provisórias e inacabadas que sejam e, $[\ldots]$ o professor de língua estrangeira deve refletir sobre [a] experiência de sua própria formação, pois necessita ter clareza sobre as possibilidades e fins do ato de se formar (ALVAREZ, 2010, p. 250).

Ou seja, para novos desafios, são necessárias novas ferramentas e profissionais com uma formação diferenciada. Mais ainda, é preciso que sejam desenvolvidas novas capacidades, novas abordagens, novos referenciais, centrados na autonomia, na reflexão, e na responsabilidade diante de sua própria prática. No cenário atual, o professor de língua estrangeira que conhece o conteúdo pedagógico, científico e cultural com o qual trabalha já não é mais suficiente. Para Imbernón (2014), 
V. 8 (3)

$402-426$ out-dez 2018

o contexto em que trabalha o magistério tornou-se complexo e diversificado. Hoje, a profissão já não é a transmissão de conhecimento acadêmico ou a transformação do conhecimento comum do aluno em um conhecimento acadêmico. A profissão exerce outras funções: motivação, luta contra a exclusão social, participação, animação de grupos, relações com estruturas sociais, com a comunidade... E, é claro, requer uma nova formação: inicial e permanente (IMBERNÓN, 2014, p. 14).

A formação que se espera hoje dos professores de línguas estrangeiras não é a de um técnico, competente no uso de modelos, conhecedor e aplicador de regras gramaticais, com proficiência na língua estrangeira, mas um profissional reflexivo, aberto, que não mais privilegie um determinado método de ensino, mas que se preocupe com a produção do conhecimento centrado na sala de aula, em constante interação entre teoria e prática (MOITA LOPES, 2001). Além disso, entende-se hoje que esse professor "não é o detentor do monopólio do saber" (VOLPI, 2001, p. 126), mas que o seu desafio atual é o de tornarse mediador e orientador do processo de ensino e aprendizagem.

Nesse sentido, é importante mencionar que alguns desses aspectos que tratam da autonomia do professor de línguas são apresentados por Kumaravadivelu (1994) e revistos em outro trabalho, publicado em 2001. Tal concepção é debatida por Silva (2004), o qual faz uma análise da proposta de Kumaravadivelu (2001), sendo que

(...) o papel do(a) professor(a) não se resume a selecionar conteúdo e escolher técnicas para aplicá-los, ele também pode possibilitar que os aprendizes reflitam sobre seu papel na sociedade, como a linguagem está estruturada e a que interesses ela serve. O trabalho em duplas e grupos pode ajudar a formar uma comunidade na qual o aprendiz pode se conscientizar do seu papel e passar a encarar o trabalho em equipe sob uma nova ótica. O que parece mais interessante aqui é que o autor passa a destacar as questões sócio-políticas que envolvem o ensino em geral e conseqüentemente o ensino/aprendizagem de LE, vendo a prática pedagógica como instrumento para a construção da cidadania do(a) aluno(a). Nessa nova concepção, a pesquisa passa a ter como foco a sala de aula, de forma que a abordagem do(a) professor(a) vai se construindo a partir de uma dinâmica entre a realidade deste, de seus/suas alunos(as) e a partir dos indícios e resultados de pesquisas da área, sejam elas de natureza teórica, empírica ou pedagógica. Sendo assim, o(a) professor(a) se torna um pesquisador capaz de indicar em que medida os achados da teoria auxiliam a sua prática. Isso pode possibilitar que ele tenha instrumentos que contribuam para que o mesmo aponte alternativas e faça adaptações capazes de surtir efeitos na sua sala de aula (SILVA, 2004, p. 06). 
O proposto por Kumaradivelu (2001) coaduna-se à proposta de Leffa (2001). Para este pesquisador, a formação dos professores de línguas estrangeiras envolve questões não apenas de ordem teórica e metodológica. Segundo Leffa (2001), "a formação de um professor de línguas envolve aspectos acadêmicos e políticos" (LEFFA, 2001, p. 351), na medida em que são também constituintes dessa formação os aspectos legais que a envolvem e a legitimam. Questões políticas relacionadas à oferta de língua estrangeira nas escolas têm definido não apenas os rumos do ensino de línguas, mas, também, os rumos da formação de professores dessas línguas em nosso país.

Celani (2009), por seu turno, aponta para a necessidade de formação continuada também para os professores de línguas estrangeiras, visto que, tanto a falta de políticas públicas direcionadas a esta área do conhecimento, quanto aos problemas decorrentes de uma formação inicial deficitária, acarretam entraves para uma prática voltada ao aprimoramento e à reflexão. Para a autora, portanto,

a falta de políticas eficazes no ensino de língua estrangeira no país, da qual decorre o mito que "língua estrangeira não se aprende na escola", a qualidade insatisfatória dos programas de formação inicial inerente à licenciatura não só dupla mas, em muitos casos, curta, fazem da formação continuada do professor de língua estrangeira uma necessidade premente (CELANI, 2009, p. 10-11, aspas da autora).

Quando se trata de formação continuada, é importante salientar, também, que a participação em eventos e palestras pode configurar-se como momento de atualização quanto a novas abordagens e métodos de ensino de línguas. Porém, não é suficiente para que o profissional construa uma reflexão mais profunda sobre a sua prática e sobre as mudanças que podem e devem ser implementadas em seu fazer pedagógico, ressignificando suas práticas (CELANI, 2009). Pósgraduações e/ou programas de aperfeiçoamento de professores podem configurar-se como exemplos importantes de formação continuada, já que possibilita aos professores pesquisar, analisar e refletir sobre sua prática, momento no qual exercem o protagonismo diante de seu processo de prática e de formação, bem como podem se inserir em diferentes projetos de pesquisa, com vistas ao seu constante aperfeiçoamento. Em suma, o processo de formação constante é inerente à profissão docente, exigindo de seus formadores e formados um comprometimento cada vez maior com a reflexão, a inovação e a tomada de decisões ante a complexidade desse processo. 
v. 8 (3)

$402-426$ out-dez 2018

No tópico a seguir, trata-se dos saberes docentes e de sua relação com a formação e a prática dos professores. As discussões baseiam-se, majoritariamente, nos estudos de Tardif (2005), autor que concebe os saberes docentes como sendo o resultado de uma produção social, fruto das interações que ocorrem entre os indivíduos. Para o autor, os saberes docentes têm um caráter plural e são mobilizados e construídos pelos professores ao longo de sua formação e de suas práticas.

\section{Saberes docentes e a formação de professores}

Em um sentido amplo, costuma-se definir os saberes docentes como sendo os conhecimentos, as atitudes e as capacidades necessárias ao exercício da profissão docente. São comuns, também, os discursos que apregoam que, para ser um bom professor, saber o conteúdo é suficiente; que os professores são dotados de um dom, uma vocação para educar, e apenas a experiência é capaz de formar o professor. Porém, todas essas afirmações não passam de concepções sobre a atividade docente baseadas no senso comum.

Os saberes docentes são classificados por Tardif (2005) em: a) saberes disciplinares: são os saberes relacionados aos campos de conhecimento teórico (ciências humanas, ciências exatas, ciências biológicas etc.). Esses saberes foram produzidos e acumulados pela sociedade, são administrados pela comunidade científica, e seu acesso se dá por meio das instituições de ensino; b) saberes da formação: são os saberes relacionados ao processo de formação inicial ou continuada de professores. Dizem respeito aos conhecimentos técnicos, pedagógicos e metodológicos necessários à prática docente; c) saberes curriculares: são os saberes relacionados à organização dos currículos escolares, dispostos na forma de objetivos, conteúdos e métodos, que constituem os programas curriculares; e d) saberes da experiência: são os saberes construídos pela e na experiência. Saberes produzidos pelos docentes a partir de suas vivências na escola, na interação com os alunos e colegas de trabalho, e são incorporados à prática na forma de habitus².

\footnotetext{
${ }^{2}$ Para Bourdieu (1989), "o habitus, como indica a palavra, é um conhecimento adquirido e também um haver, um capital (de um sujeito transcendental na tradição idealista) o habitus, a hexis, indica a disposição incorporada, quase postural" (BOURDIEU, 1989, p. 61, grifo do autor). No campo da educação, o habitus consiste em um conjunto de disposições que orientam as práticas pedagógicas dos professores e determinam sua postura, suas escolhas, sua abordagem (NOGUEIRA; CATANI, 2013).
} 
Em um exercício de situar historicamente a atividade educacional, Tardif (2005) aponta que, durante muito tempo, esta atividade foi vista como uma arte. Já na era moderna, passou a ser vista como uma técnica e, mais recentemente, passou a ser considerada como uma interação. Em sua atuação na prática cotidiana escolar, o professor faz uso de diferentes saberes, advindos das variadas dimensões que compõem o ensino. O trabalho docente e as relações estabelecidas nele é que determinam quais saberes são mobilizados para enfrentar e solucionar os problemas do cotidiano. Para Tardif (2005),

\begin{abstract}
A questão dos saberes está intimamente ligada à questão do trabalho docente no ambiente escolar, à sua organização, à sua diferenciação, à sua especialização, aos condicionantes objetivos e subjetivos com os quais os professores têm que lidar, etc. Ela também está ligada a todo o contexto social no qual a profissão docente está inserida e que determina, de diversas maneiras, os saberes exigidos e adquiridos no exercício da profissão (TARDIF, 2005, p. 218).
\end{abstract}

Nunes (2001) traça um breve panorama da pesquisa brasileira sobre os saberes docentes. Segundo a autora, na década de 1990, o Brasil lança mão de novos enfoques e paradigmas para compreender as práticas pedagógicas e os saberes docentes, a fim de buscar resgatar o papel do professor e pensar a formação para além da academia (NUNES, 2001, p. 28). Ainda sobre os estudos dessa temática no contexto brasileiro, Tardif (2005) afirma que,

No Brasil, sobretudo a partir do início dos anos 90, a pesquisa educacional passou a vislumbrar, na sala de aula, um espaço rico em possibilidades de investigação. Um número cada vez maior de pesquisadores da área da educação tem ido regularmente às instituições escolares observar e analisar as atividades cotidianas dos trabalhadores do ensino (TARDIF, 2005, p. 112).

Tardif (2005) busca tratar da questão dos problemas enfrentados na formação de professores na contemporaneidade, dentre eles a relação entre a teoria e a prática na formação docente. O autor destaca que existe uma diferença muito grande entre os conhecimentos produzidos pela academia e o que de fato se realiza na escola. Para o autor, o saber dos professores tem caráter social na medida em que é um saber compartilhado por profissionais que atuam em uma mesma organização, com objetos e práticas de caráter social. Além disso, os saberes docentes têm uma origem social, pois não se originam apenas nos professores, mas que estão "de um certo modo, na confluência de 
v. 8 (3)

$402-426$ out-dez 2018

vários saberes oriundos da sociedade, da instituição escolar, dos outros atores educacionais, das universidades, etc." (TARDIF, 2005, p. 19). Ou seja, a prática pedagógica só tem êxito na medida em que os saberes docentes são acionados, construídos e compartilhados entre todos os agentes envolvidos nos processos de ensino e aprendizagem, nos mais variados contextos educacionais.

Posteriormente, ao apresentarmos a análise de diferentes excertos coletados em relatórios de estágio, produzidos a partir da experiência de alunos professores de Letras-Espanhol, os saberes docentes apresentados neste item permitem que analisemos, por exemplo, questões referentes ao domínio da Língua Espanhola e dos conteúdos que deverão ser trabalhados em sala de aula, além da influência da língua materna no processo de ensino e de aprendizagem de língua estrangeira e das metodologias inerentes a esses processos. No entanto, antes de partirmos para as análises, discutiremos acerca do papel do estágio nos cursos de Letras.

\section{O papel do estágio supervisionado na licenciatura em Letras}

Um dos objetivos dos cursos de licenciatura é o de oferecer os subsídios teóricos e práticos (ou teórico-práticos) necessários ao cumprimento das funções profissionais, de acordo com cada área de conhecimento. Mas, para além disso, é primordial também apresentar aos acadêmicos atividades que promovam a reflexão não só do ponto de vista do conhecimento científico, mas, também, de seu contexto de formação e atuação, dos fundamentos da educação e das dimensões ética, política e ideológica de seu trabalho. Dessa forma,

durante o curso de graduação começam a ser construídos os saberes, as habilidades, posturas e atitudes que formam o profissional. Em períodos de estágio, esses conhecimentos são ressignificados pelo aluno estagiário a partir de suas experiências pessoais em contato direto com o campo de trabalho que, ao longo da vida profissional, vão sendo reconstruídos no exercício da profissão (ALMEIDA; PIMENTA, 2014, p. 73).

O período de atuação que faz parte da carga horária a ser cumprida durante a disciplina de estágio supervisionado tem como intuito permitir que o acadêmico faça um primeiro contato com a realidade escolar, se este ainda não é um professor, aproximando o aluno professor do contexto no qual ele atuará enquanto profissional. Para Pimenta e Lima (2012), "é necessário, pois, que as atividades 
desenvolvidas no decorrer do curso de formação considerem o estágio como espaço privilegiado de questionamento e investigação" (PIMENTA; LIMA, 2012, p. 112). No entanto, há autores que salientam a questão da desvalorização das disciplinas de estágio supervisionado, por serem "concebidas como o momento da prática na formação inicial do professor, desprovidas do valor simbólico impregnado nas demais disciplinas, identificadas como teóricas" (SILVA, 2014, p. 30). Sendo assim, a dimensão prática dessas disciplinas é tão relevante quanto a dimensão teórica, uma vez que teoria e prática são conceitos e aspectos indissociáveis da formação docente.

A burocratização dos procedimentos que envolvem o estágio supervisionado é muito comum. Acadêmicos e professores formadores voltam sua atenção para elementos organizacionais e se esquecem de refletir e analisar criticamente a atuação e, consequentemente, o processo de formação. Silva (2014) tem se dedicado a investigar o processo de escrita reflexiva de alunos professores. Os relatórios de estágio supervisionado elaborados por estes têm se constituído em corpus de análise e de reflexão também para os professores formadores. Para Perrenoud (2002, p. 72, aspas do autor), "ao assumir a formação dos professores, com frequência as universidades resistem quando têm de integrar esses 'saberes práticos' ao seu currículo", o autor destaca ainda que, por esse motivo, a abordagem desses saberes "é delegada aos responsáveis pelos estágios e aos estabelecimentos escolares (PERRENOUD, 2002, p. 72-73). Nesse sentido, tem-se clareza de que a formação inicial dos professores deve ser baseada na investigação da realidade, refletindo sobre esta, a fim de avaliarem, professores formadores de todas as disciplinas das licenciaturas e alunos professores, seu papel e sua atuação nesse processo.

Outra dimensão importante quanto aos encaminhamentos que estão relacionados ao processo de estágio supervisionado nas licenciaturas diz respeito aos aspectos que envolvem os procedimentos de organização e avaliação da disciplina. Sobre isso, Barreiro e Gebran (2006) criticam o modelo burocratizado de muitos programas, afirmando que:

De modo geral, os estágios têm se constituído de forma burocrática, com preenchimento de fichas e valorização de atividades que envolvem observação participação e regência, desprovidas de uma meta investigativa. Dessa forma, por um lado se reforça a perspectiva do ensino como imitação de modelos, sem privilegiar a análise crítica do contexto escolar, 
v. 8 (3)

$402-426$ out-dez 2018

da formação de professores, dos processos constitutivos da aula e, por outro, reforçam-se práticas institucionais não reflexivas, presentes na educação básica, que concebem o estágio como o momento da prática e de aprendizagens de técnicas do bemfazer (BARREIRO; GEBRAN, 2006, p. 26-27).

Diantedaquestãodanãoreflexividadeedoestágiosupervisionado concebido como momento dedicado à prática citados por Barreiro e Gebran (2006), é importante destacar que esse modelo de formação docente não pode mais fazer parte da realidade das instituições formadoras. A fim de romper com essa prática reprodutora, o estágio supervisionado precisa configurar-se como um momento de comprometimento com a prática, com a reflexão, com a tomada de decisões, de confronto entre práticas e teorias, e produção de novos conhecimentos a partir da atuação, tal como afirmam Barreiro e Gebran (2006):

Nesse sentido, a formação para a docência de qualidade deve se pautar na perspectiva investigativa, na qual a pesquisa, assumida como princípio científico e educativo, apresentase como uma proposição metodológica fundamental para o rompimento das práticas de reprodução (BARREIRO; GEBRAN, 2006, p. 118).

Neste sentido, o estágio supervisionado permite ao futuro profissional docente conhecer, analisar e refletir sobre seu ambiente de trabalho. Além disso, o aluno de estágio precisa enfrentar a realidade provido das teorias que aprende ao longo da graduação, das reflexões que faz a partir da prática que observa, de experiências que viveu e que vive enquanto aluno, das concepções que carrega sobre o que é ensinar e aprender, além das capacidades que aprendeu a desenvolver ao longo da licenciatura que cursou. Assim, conforme Stutz e Cristóvão (2013),

a complexidade e amplitude do estágio demandam uma vasta gama de saberes profissionais teórico-práticos. Esses saberes são a base para a construção de capacidades docentes, vistas como o conjunto de aptidões relacionadas ao gênero profissional docente (STUTZ; CRISTÓVÃO, 2013, p. 197).

O estágio supervisionado propicia ao futuro profissional docente conhecer, analisar e refletir sobre sua área de atuação. Dessa forma, "considerar o estágio como campo de conhecimento significa atribuir-lhe um estatuto epistemológico que supere sua tradicional redução à atividade prática instrumental" (PIMENTA; LIMA, 2012, p. 29). Os processos educativos, realizados em diferentes espaços sociais, capazes de modificar os agentes envolvidos nesse processo, caracterizam 
a educação como uma práxis social complexa (ALMEIDA; PIMENTA, 2014). O profissional docente afeta e é afetado direta ou indiretamente pelas circunstâncias que o cercam, seja do ponto de vista pedagógico, social, político, histórico etc. Sua práxis está estreitamente ligada à sua prática ${ }^{3}$, estabelecendo a necessidade de conhecer para compreender e, posteriormente, transformar a realidade na qual atua.

Há, ainda, vários autores (GIMENEZ; CRISTÓVÃO, 2004; SILVA, 2014; SCHÖN, 2008) que tratam do distanciamento existente entre os mundos da escola e da universidade. O momento das práticas e do estágio, muitas vezes, configura-se como um dos únicos momentos em que se suplanta o abismo existente entre os saberes trabalhados na universidade e os saberes oriundos da experiência pedagógica. Gimenez e Cristóvão (2004) comungam dessa ideia quando afirmam que a escola, enquanto "comunidade de prática", deve ser entendida não como mero espaço de atuação, mas, sim, como espaço de integração entre universidade e escola.

Tendo sido apresentadas algumas considerações sobre o papel do estágio supervisionado e seu papel na formação docente, a seguir apresentamos e analisamos parte do corpus da presente pesquisa.

\section{Aspectos metodológicos e análise dos dados}

Esta é uma pesquisa de abordagem qualitativa, tendo em vista a especificidade do corpus, a saber, relatórios de estágio. Por tratar-se de uma pesquisa qualitativa, de caráter interpretativista (ERICKSON, 1989; MOITA LOPES, 1994), que envolve análise documental, entendese que a interpretação é necessária para se compreender a realidade e os significados que constituem o objeto de investigação. O corpus desta pesquisa consiste em um conjunto de relatórios de estágio, que são classificados como documentos do tipo técnico (SEVERINO, 2015; LÜDKE; ANDRÉ, 1986), elaborados com o intuito de sistematizar práticas pedagógicas realizadas anteriormente, as quais descrevem os procedimentos de ação e de articulação entre a teoria aprendida e a prática vivenciada. Cabe mencionar que a coleta de dados teve todos os procedimentos éticos assegurados, por meio de preenchimento de TCLE (Termo de Consentimento Livre e Esclarecido).

${ }_{3}^{3}$ Cabe apresentar aqui a diferença entre Práxis e Prática Docente. Sacristán (1999 apud PIMENTA; LIMA, 2012, p. 41) afirma que a prática "é institucionalizada; são as formas de educar que ocorrem em diferentes contextos institucionalizados". Azzi (2014, p. 52) define Práxis como sendo a "relação teoria-prática da ação docente". 
V. 8 (3)

$402-426$ out-dez 2018

Considerando os saberes propostos por Tardif (2005), quais sejam: saberes disciplinares, saberes da formação, saberes curriculares e saberes da experiência, neste artigo primamos por analisar os saberes advindos da formação, sobretudo por estes contemplarem as discussões presentes no momento do estágio supervisionado, ou seja, o momento em que há esta intrínseca relação entre teoria e prática. Para esta análise, foram selecionados 08 (oito) excertos, os quais apresentam, em grande medida, a categoria analítica escolhida. Os relatórios de estágio selecionados, de onde foram coletados os excertos analisados neste artigo, foram produzidos em Língua Espanhola, nas disciplinas de Estágio Supervisionado I e II, da licenciatura em Letras-Espanhol, em uma universidade pública do Centro-Sul do Paraná.

Os relatórios foram elaborados após o cumprimento total da carga horária, correspondente a 10 horas/aula de observação e 30 horas/ aula de atuação. Os acadêmicos autores dos relatórios de estágio, na ocasião da coleta, tinham idades entre 20 e 40 anos e, em sua maioria, residem em cidades da região Centro-Sul do Paraná. À época da realização dos estágios supervisionados, alguns deles eram trabalhadores em suas cidades e outros eram beneficiados por bolsas em programas como PIBID (Programa Institucional de Bolsas de Iniciação à Docência) e IC (Programa de Iniciação Científica).

Para Tardif (2005), os saberes da formação são os relacionados aos conhecimentos pedagógicos e metodológicos aprendidos ao longo da formação docente. São os saberes pertinentes ao processo de formação inicial ou continuada de professores e dizem respeito aos conhecimentos técnicos, pedagógicos e metodológicos necessários à prática docente. Além disso, fazem parte dos saberes da formação os conhecimentos relacionados ao conteúdo que deve ser ensinado na escola.

A esse respeito, os excertos apresentados a seguir trazem especificidades relacionadas aos saberes do professor de línguas estrangeiras e a ocorrência de descrições e reflexões acerca dos conteúdos a serem ensinados, destacando em alguns dos excertos, inclusive, as questões metodológicas pertinentes a esses conteúdos.

Tendo como base os saberes da formação, nos excertos que são apresentados a seguir, estão presentes nos textos dos alunos professores o destaque a aspectos relacionados à articulação entre os saberes relativos à língua materna e à língua estrangeira. Para começar, no excerto 01, o aluno professor faz referência à influência que a língua materna pode exercer no processo de aquisição de uma L2 (Segunda Língua), porém 
não explica como se daria essa influência. Além disso, o aluno professor, autor do excerto 01, destaca a necessidade de se trabalhar também aspectos socioculturais relativos ao idioma que se ensina, entendendo que a língua pertence a "a un amplio espacio sociocultural".

\section{Excerto 01}

La enseñanza de lenguas extranjeras no debe limitarse al desarrollo del aprendizaje solo de sus estructuras gramaticales, sino también considerar que una lengua pertenece a un amplio espacio sociocultural del otro. En esta perspectiva, cabe al profesor buscar estrategias de aprendizaje para interrelacionar los diversos elementos que constituyen una lengua, además de llevar en cuenta las influencias que la lengua materna puede causar en la adquisición de una L2 (Relatório 12, Conclusão, p. 22, 2014).

Nos excertos 02 e 03, são elencadas questões referentes às quatro habilidades, propostas pela abordagem comunicativa. Esta abordagem surge nos anos 1970, na Europa, e apresentou uma série de princípios norteadores da prática docente (VIEIRA-ABRAHÃO, 2010). De modo geral, o que se percebe nos relatórios analisados é que muitos dos alunos professores preconizam o uso da abordagem comunicativa em suas aulas, baseando-o no trabalho com as quatro habilidades, conforme aparecem nos excertos 02 e 03, uma vez que esta abordagem representa o modelo de ensino experimentado por eles durante a graduação. Leffa (2001, p. 334) destaca que a formação do professor de línguas estrangeiras envolve o "domínio de diferentes áreas de conhecimento", sejam elas linguísticas, pedagógicas ou metodológicas, necessárias à prática docente. Ainda com relação a isso, Tardif (2005) considera o conhecimento do conteúdo a ser ensinado parte fundamental do conhecimento pedagógico. No entanto, segundo ele, "conhecer bem a matéria que se deve ensinar é apenas uma condição necessária, e não uma condição suficiente, do trabalho pedagógico" (TARDIF, 2005, p. 120). Nesse caso, pelos excertos a seguir (02 e 03), podemos inferir que os alunos, de certa forma, compreendem as habilidades linguísticas como conteúdos a serem ensinados e não como meios tal, o que compromete o desenvolvimento dos conteúdos em sala de aula, pois se tem a preocupação constante em atender o que preconiza uma dada metodologia. 
V. 8 (3)

402-426

out-dez

2018

\section{Excerto 02}

Durante mis prácticas he intentado hacer con que los alumnos utilizasen las cuatro habilidades lingüísticas para que aprendiesen y dominasen la lengua en todos los aspectos. La habilidad de leer fue trabajada principalmente a través de la lectura de textos de varios géneros y de interpretación... (Relatório 14, Relatório de Atuação, p. 13, 2014).

\section{Excerto 03}

En las primeras clases fueran adoptadas metodologías que daban un mayor enfoque a contenidos comunicativos, llevando en cuenta el desarrollo de las cuatro destrezas del lenguaje, la comprensión oral, la expresión oral, comprensión escrita y la expresión escrita (Relatório 17, Relatório de Atuação, p. 10, 2015).

No que se refere às metodologias de ensino, sendo elas constitutivas dos saberes da formação, apresentam-se, a seguir, 03 (três) excertos em que os alunos professores, autores dos relatórios analisados, destacam elementos desta temática:

\section{Excerto 04}

.... apesarde trabajar los mismos contenidos la metodologíanisiempre era la misma, pues tenía que adaptarla a las especificidades del grupo para que consiguiesen comprender y asimilar los contenidos (Relatório 14, Relatório de Atuação, p. 16, 2014).

\section{Excerto 05}

...se percibe que cabe al profesor tener el conocimiento de los métodosy de las metodologías, del nivel de conocimientos de los alumnos, de los dominios que ya tienen y la autonomía al utilizar los distintos métodos, teniendo en vista las necesidades que un salón de clase heterogéneo presenta (Relatório 11, Relatório de Atuação, p. 16, 2014).

\section{Excerto 06}

Las metodologías que utilicé para las clases de prácticas fueron la tradicional y la comunicativa. Eso se explica por virtudes de los alumnos resistieren un poco con relación a las conversaciones en el salón de clase por motivos de timidez o miedo de causar errores (Relatório 18, Relatório de Atuação, p. 11, 2015). 
Nos excertos 04 e 05, o aluno professor ressalta a importância do conhecimento dos diferentes métodos, para proceder à escolha do que melhor convém às características do grupo com o qual se vai trabalhar, dadas as características heterogêneas do público alvo. Destaca-se, também, a autonomia do professor em analisar e refletir acerca de quais metodologias melhor respondem ao desafio de ensinar. No excerto 06, o aluno professor relata que utilizou as metodologias tradicional e comunicativa. A primeira se caracteriza pelo trabalho focado na estrutura da língua e em seus aspectos gramaticais, enquanto a segunda trabalha o potencial funcional e comunicativo da língua, enfatizando as necessidades e preferências dos alunos (RICHARDS; RODGERS, 2001). A alternância entre uma metodologia e outra, segundo o aluno professor, deu-se pela resistência apresentada pelos alunos diante da exposição em exercícios de conversação. Por meio do trabalho de Silva (2004), observa-se que esta mudança entre uma metodologia e outra é plausível, já que, na era Pós-Método, as metodologias podem e devem ser adaptadas pelo professor tendo em vista seu público e contexto.

O autor do excerto 07 fala da impossibilidade de utilização de planejamentos de aula iguais para diferentes turmas, dadas as características heterogêneas desses grupos e a importância de se pensar metodologias e materiais de acordo com os interesses, as necessidades e o nível linguístico de cada uma das classes em que se atua. Para chegar a essa constatação, o autor se baseou, provavelmente, nas discussões realizadas ao longo de seu processo de formação, mas, também, nas experiências que vivenciou na atuação realizada. Neste sentido, é importante observar que o aluno professor se vale do papel da reflexão relacionado à sua experiência de prática.

\section{Excerto 07 \\ [...] no es posible afirmar que un plan de clase puede ser apto para cualquier turma. A pesar de llevarnos como ejemplo algunas de las metodologías usadas por la profesora regente, tenemos que estar preparados y actualizados siempre (Relatório 18, Conclusão, p. 18-19, 2015).}

Já no excerto 08, a reflexão aparece associada à formação docente. Nesse caso, o aluno professor acredita que a experiência propiciada pelo estágio supervisionado permite a ampliação dos conhecimentos acerca dos saberes relacionados à formação e à reflexão a respeito de todo esse processo: 
V. 8 (3)

$402-426$

out-dez

2018

\section{Excerto 08}

[...] el objetivo principal de las prácticas es propiciar al académico la ampliación de sus conocimientos en relación a la construcción de la formación docente, en su actuación, en el desarrollo de sus competencias, en las reflexiones del ser y del saber docente y en sus interpretaciones y destrezas (Relatório 11, Introdução, p. 4, 2014).

Para o aluno professor, autor do excerto 08, o estágio é constitutivo da formação do professor, uma vez que esta formação é possibilitada pela atuação e pelas reflexões do ser e do saber docente. Conforme vimos a respeito dos saberes docentes, a partir dos estudos de Tardif (2005), os saberes da formação profissional são trabalhados nas licenciaturas, porém, a esses saberes, agregam-se as experiências vividas pelos próprios professores em sua prática, pois, segundo Tardif (2005, p. 37), algumas ciências não se ocupam apenas de produzir conhecimento, "mas procuram também incorporá-los à prática do professor". A disciplina de Estágio Supervisionado, por sua vez, prevê discussões acerca do ensino da Língua Espanhola por meio da consideração e prática de procedimentos e estratégias diversas, buscando desenvolver no aluno professor um conhecimento mais aprofundado a respeito das concepções, procedimentos e estratégias de ensino e aprendizagem de Espanhol como língua estrangeira. A disciplina de estágio, portanto, se apresenta como espaço de discussão e reflexão sobre as práticas e sobre a formação do aluno professor de Letras-Espanhol.

\section{Considerações Finais}

Os saberes são construídos na atividade pedagógica, baseados na articulação da teoria e da prática. Logo, os cursos de formação de professores de línguas estrangeiras se configuram como espaços de articulação dos saberes docentes, uma vez que estão presentes neles as condições para que a práxis aconteça, permitindo que novos saberes sejam construídos. No sentido de buscar superar o modelo de professor aplicador de métodos, transmissor de conhecimentos, que não reflete sobre a sua prática, as licenciaturas em Letras precisam cumprir seu papel de formadoras. 
A formação acadêmica dos professores de línguas estrangeiras não pode estar focada apenas nos saberes advindos das teorias, mas deve proporcionar, aos futuros professores, os saberes advindos das práticas e da reflexão sobre essas práticas, pois a experiência por si só não é capaz de formar. É preciso que haja reflexão sobre essa prática, além do compartilhamento dos saberes disciplinares, da formação e experiências com outros professores. Tal fato pode se dar a partir da aproximação entre as áreas que se denominam teóricas com as aplicadas. A Linguística Aplicada, como uma ciência, tem um papel fundamental nesse processo. No entanto, tem-se a impressão de que, nos cursos de formação de professores de línguas, prevalece certa distância entre o campo da teoria e da prática.

O estágio supervisionado na licenciatura em Letras tem como finalidade permitir que os acadêmicos, alunos professores, possam experimentar seu campo de atuação profissional munidos dos conhecimentos e das condições, mesmo que iniciais, para a prática pedagógica. No contexto educacional, os professores de línguas estrangeiras mobilizam os saberes pertinentes à especificidade de sua prática. As licenciaturas em Letras, nesse sentido, têm o papel de discutir a questão dos saberes, levando em conta as demandas dos contextos nos quais os alunos professores atuarão, sobretudo, aos cursos que se destinam à formação para atuação na Educação Básica e no Ensino Superior.

Por meio dos dados analisados, podemos elencar um conjunto de conhecimentos - saberes - que perpassam a fase em que o aluno professor experimenta a prática docente, ainda em formação, entre eles: a questão da língua em uso, suas diferentes facetas e inter-relações, tanto no plano discursivo quanto linguístico; as metodologias de ensino de línguas e os dilemas entre o que é considerado tradicional e comunicativo; as quatro habilidades linguísticas, tal como se convencionou chamar na abordagem comunicativa o desenvolvimento de práticas linguísticas orais e escritas e, por fim, a reflexão sobre o processo de formação docente como uma competência a ser desenvolvida.

Tendo em vista os dados apresentados, há indicativos de que os saberes da formação são amplamente mobilizados pelos alunos professores no momento em que são convocados a refletirem sobre suas práticas, as quais conduzem a decisões acerca dos conteúdos e estratégias de ensino que precisam estar contempladas nos cursos de licenciatura. Nesse sentido, questões relacionadas à autonomia, à 
v. 8 (3)

$402-426$ out-dez 2018

reflexão e à produção de conhecimento necessitam ser abordadas nas disciplinas de estágio supervisionado, uma vez que são imprescindíveis ao processo de formação e na mobilização de seus saberes. Trata-se, portanto, de uma tarefa que se dá na própria articulação teoria-prática, trabalho que não se faz somente no estágio, mas deveria perpassar todo o processo de formação docente.

O papel das instituições formadoras, portanto, é o de proporcionar a construção desses saberes por meio da experiência na prática docente. Sendo assim, é preciso que os saberes docentes, e todas as dimensões que os envolvem, ganhem cada vez mais espaço nos currículos das licenciaturas, pois esses saberes, sendo constitutivos da atividade docente, não podem restar desconectados das discussões pertinentes à formação de professores.

\section{Referências}

ALMEIDA, Maria I.; PIMENTA, Selma G. Estágios supervisionados na formação docente. São Paulo: Cortez, 2014.

ALVAREZ, Maria L. O. O papel dos cursos de Letras na formação dos professores de línguas: ontem, hoje e sempre. In: SILVA, Kleber A. (Org.). Ensinar e aprender línguas na contemporaneidade: linhas e entrelinhas. Campinas: Pontes, 2010. p. 235-255.

ALVES, Wanderson F. A formação de professores e as teorias do saber docente: contextos, dúvidas e desafios. Educação e Pesquisa, v. 33, n. 2, p. 263-280, 2007.

AZZI, Sandra. Trabalho docente: autonomia didática e construção do saber pedagógico. In: PIMENTA, Selma G. (Org.). Saberes pedagógicos e atividade docente. São Paulo: Cortez, 2014. p. 39-69.

BARREIRO, Iraíde M. F.; GEBRAN, Raimunda A. Prática de ensino e estágio supervisionado na formação de professores. São Paulo: Ed. Avercamp, 2006.

BOURDIEU, Pierre. O poder simbólico. Rio de Janeiro: Ed. Beltrand, 1989.

BRASIL. Ministério da Educação e do Desporto. Parâmetros Curriculares Nacionais - Língua Estrangeira (PCN-LE). Brasília, 1998. Disponível em: $<$ http://portal.mec.gov.br/seb/arquivos/pdf/pcn_estrangeira.pdf $>$. Acesso em: 10 maio 2018.

CELANI, Maria A. A. Prefácio. In: TELLES, João A. (Org.). Formação inicial e continuada de professores de línguas: dimensões e ações na pesquisa e na prática. Campinas: Pontes, 2009. p. 9-12.

DORNELLES, Clara; IRALA, Valesca B. O diário de formação em um programa de iniciação à docência: imaginários e dilemas dos escreventes. In: REICHMANN, Carla L. (Org.). Diários reflexivos de professores de línguas: ensinar, escrever, refazer(-se). Campinas/SP: Pontes, 2013. p. 17-38. 
ERICKSON, Frederick. Métodos cualitativos de investigación sobre la enseñanza. In: La investigación de la enseñanza II: métodos cualitativos y de observación. Barcelona: Paidós Ediciones, 1989. p. 195-295.

GAUTHIER, Clermonnt et al. Por uma teoria da pedagogia: pesquisas contemporâneas sobre o saber docente. Ijuí: Ed. Unijuí, 2006.

GIMENEZ, Telma N.; CRISTÓVÃO, Vera L. L. Derrubando paredes e construindo pontes: formação de professores de língua inglesa na atualidade. Revista Brasileira de Linguística Aplicada (RBLA), v. 4, n. 2, p. 85-95, 2004.

GHIRALDELLI JR., Paulo. História da educação brasileira. São Paulo: Cortez, 2009.

IMBERNÓN, Francisco. Formação docente e profissional: formar-se para a mudança e a incerteza. São Paulo: Cortez, 2014.

KUMARAVADIVELU, B. The post-method: (E)merging strategies for second/ foreign language teaching. In: TESOL Quarterly 28, p. 27-48, 1994.

$60,2001$.

Toward a postmethod pedagogy. In: TESOL Quarterly 35, p. 537-

LEFFA, Vilson J. Aspectos políticos da formação do professor de línguas estrangeiras. In:

(Org.). 0 professor de línguas: construindo a profissão. Pelotas: Ed. Educat, 2001. p. 333-355.

. O ensino de línguas estrangeiras no contexto nacional. Contexturas, APLIESP, n. 4, p. 13-24, 1999.

LÜDKE, Menga; ANDRÉ, Marli E. D. A. Pesquisa em educação: abordagens qualitativas. São Paulo: EPU, 1986.

MOITA LOPES, Luiz P. Oficina de linguística aplicada: a natureza social e educacional dos processos de ensino/aprendizagem de línguas. Campinas/SP: Mercado de Letras, 2001.

Pesquisa interpretativista em linguística aplicada: a linguagem como condição e solução. D.E.L.T.A, v. 10, n. 2, p. 329-338, 1994.

NOGUEIRA, Maria A.; CATANI, Afrânio (Orgs.). Pierre Bourdieu: escritos de educação. Petrópolis/RJ: Vozes, 2013.

NÓVOA, António. Nada substitui o bom professor. In: FARO, J. S.; GUTIERRE, P. (Ed.). Desafios do trabalho do professor no mundo contemporâneo (livreto). São Paulo: SINPRO/SP, 2007. Disponível em: <http://www.sinprosp.org.br/ arquivos/novoa/livreto_novoa.pdf>. Acesso em: 11 maio 2018.

(Org.). Profissão professor. Porto: Porto Editora, 1999.

NUNES, Célia M. F. Saberes docentes e formação de professores: um breve panorama da pesquisa brasileira. Educação \& Sociedade, ano XXII, n. 74, p. 27-42, abr. 2001.

NUNES, Lucia M. Aprender uma língua estrangeira é sempre um pouco tornar-se um outro. In: SALEH, Pascoalina B. O; OLIVEIRA, Silvana (Org.). 
V. 8 (3)

402-426 out-dez 2018

Linguagem, texto e ensino: discussões do CELLIP. Ponta Grossa/PR: Editora UEPG, 2010. p. 93-102.

PAGNI, Pedro A. Do manifesto de 1932 à construção de um saber pedagógico: ensaiando um diálogo entre Fernando de Azevedo e Anísio Teixeira. Ijuí: Editora Unijuí, 2000.

PERRENOUD, Philippe. A prática reflexiva no ofício do professor: profissionalização e razão pedagógica. Porto Alegre: Artmed, 2002.

PIMENTA, Selma G.; LIMA, Maria S. L. Estágio e docência. São Paulo: Cortez, 2012.

RICHARDS, J. C.; RODGERS, T. S. Enfoque y métodos en la enseñanza de idiomas. Madrid: Cambridge, 2001.

SCHÖN, Donald A. Educando o profissional reflexivo: um novo design para o ensino e a aprendizagem. Porto Alegre: Artmed, 2008.

SEVERINO, Antônio J. Metodologia do trabalho científico. São Paulo: Cortez, 2015.

SILVA, Gisvaldo A. A era pós-método: o professor como um intelectual. Linguagens \& Cidadania, v. 6, n. 2, jul.7dez. 2004.

SILVA, Wagner R. Reflexão pela escrita no estágio supervisionado da licenciatura: pesquisa em linguística aplicada. Campinas/SP: Pontes, 2014.

STUTZ, Lidia; CRISTÓVÃO, Vera L. L. Socialização de diários: um instrumento para a reflexividade no estágio supervisionado em língua inglesa. In: REICHMANN, Carla L. (Org.). Diários reflexivos de professores de línguas: ensinar, escrever, refazer(-se). Campinas/SP: Pontes, 2013. p. 197-221.

TARDIF, Maurice. Saberes docentes e formação profissional. Petrópolis: Vozes, 2005.

VIEIRA-ABRAHÃO, Maria H. A formaç̃̃o de professores de línguas: passado, presente e futuro. In: SILVA, Kleber A. (Org.). Ensinar e aprender línguas na contemporaneidade: linhas e entrelinhas. Campinas: Pontes, 2010. p. 225-233.

VOLPI, Marina T. A formação de professores de língua estrangeira frente aos novos enfoques de sua função docente. In: LEFFA, Vilson J. (Org.). O professor de línguas: construindo a profissão. Pelotas: Ed. Educat, 2001. p. 125-133. 